\title{
What derives lean manufacturing effectiveness: An interpretive structural model
}

\author{
TanChing $\mathrm{NG}^{1}{ }^{1}$, Morteza Ghobakhloo ${ }^{2}$ \\ ${ }^{1}$ Department of Mechanical and Material Engineering, Universiti Tunku Abdul Rahman, Selangor, Malaysia \\ ${ }^{2}$ Department of Management and Economics, Tarbiat Modares University, Tehran, Iran
}

\section{A R T I C L E IN F O}

\section{Article history:}

Received 17 April 2017

Received in revised form

13 July 2017

Accepted 14 July 2017

\section{Keywords:}

Lean manufacturing

Effectiveness

ISM

\begin{abstract}
A B S T R A C T
This research aims to model the processes through which manufacturing firms can increase the effectiveness of lean manufacturing practices. To achieve its objective this research benefits from the interactive structural modelling technique to first capture the opinions of lean experts and further map the interrelationships between determents of lean manufacturing effectiveness. Findings revealed that employees empowerment, employees involvement, implementation cost, teamwork, managerial leadership and support, awareness of latest lean information and information technology are key determinants of lean manufacturing effectiveness. Findings explain that the precedence relationships between the determining factors identified, and the order of their implementation is crucial to the achievement of highest degrees of lean manufacturing effectiveness. Utility of the proposed interpretive structural modelling methodology imposing order, direction and significance of the relationships among elements of lean manufacturing effectiveness are expected to offer considerable value to the decision makers and lean practitioners.
\end{abstract}

(c) 2017 The Authors. Published by IASE. This is an open access article under the CC BY-NC-ND license (http://creativecommons.org/licenses/by-nc-nd/4.0/).

\section{Introduction}

Due to the rapid changing and globalization in every industry, a great interest topic to organizations today is the improvement of overall performance and productivity. Lean Manufacturing (LM) as one of the well-known systems that could possibly results in productivity improvement became a visible trend in most of the manufacturing industries in Malaysia from last few decades. Today, "lean" may no longer be fashionable but its core principles (flow, value, pull, minimizing waste and etc.) have become the paradigm for a significant number of manufacturing (and service) operations (Womack and Jones, 2010). The main purpose of LM is to increase the productivity by increasing the output product, and decrease the input factors such as processing time, transportation time, man power, raw materials and other inputs that are involved the consumption of time and cost of manufacturing. With the aid of LM systems, the improvement will be able to contribute a high profit margin to the company as LM

\footnotetext{
* Corresponding Author.

Email Address: ngtc@utar.edu.my (N.G. TanChing) https://doi.org/10.21833/ijaas.2017.08.015

2313-626X/C 2017 The Authors. Published by IASE.

This is an open access article under the CC BY-NC-ND license

(http://creativecommons.org/licenses/by-nc-nd/4.0/)
}

constantly adjusts the manufacturing process to achieve savings and quality improvements (Lapinski, 2006). Despite of LM already widely implemented in various industries for few decades and significant number of researches on its profitability and benefits already published in various journal papers, the key determinants of LM effectiveness is still a major concern. Meanwhile, doubt raised against the effectiveness of LM was described in the paper from Busch (2010), published in the Supply Chain Digest, which questioned whether Lean would be the main reason that causing the recalling of certain Toyota models, as lean is more focus on the productivity rather than the quality of products produced. Fliedner and Majeske (2010) mentioned on the methods to make LM effect longer, but still without clear statement of how long does LM can be actually effective and the key determinants of LM successful implementation. With rising doubts among the industries, the study on the key determinants of LM effectiveness is crucial to the current and even future LM implementation. Furthermore, the analysis and determination of precedence relationship between key determinants of LM effectiveness is not solely benefit to the current manufacturing industries, but also laying the foundation for future development of LM. Hence, this paper will collect qualitative data and analyses the key determinants of Malaysia's LM 
effectiveness in different categories of manufacturing industries by using Interpretive Structural Modeling. Moreover, this paper will determine the precedence relationship between each key determinants of LM effectiveness. By having deeper understanding on the precedence relationship among key determinants, this paper can act as a reference for interest parties in order to implement LM more effectively and efficiently. At the end of this paper, the mechanism of LM effectiveness level in Malaysia will be determined. After the introduction, literature review will be given in section 2 and followed by problem description in section 3. Section 4 explains the research methodology in details while section 5 consists of the application model. The results analysis and discussion are presented in section 6 . The conclusion of this paper is presented in the final section.

\section{Literature review}

Nowadays, LM became an essential and indispensable manufacturing practice for the manufacturing plants in U.S, Japan, and Europe, and even in the developing countries (Anand and Kodali, 2009; Yang et al., 2011). With most of the researchers and implementers agreed with the advantages and benefits introduced by LM (Shah and Ward, 2003), it is still lacking of common literature review against key determinants of LM (MoyanoFuentes et al., 2012; Shah and Ward, 2007). From the current review it can be presumed that LM is undoubtedly a multifaceted idea that can be gathered together as different types of organizational practices (Moyano-Fuentes et al., 2012). In order to determine the key determinants of LM implementation and precedence relationship among key determinants, interpretive structural modelling is one of the suitable tools to achieve the results.

ISM was created by Warfield (1974) as described as a "methodology which employs graphics and words in carefully defined patterns to portray the structure of a complex issue, a system or a field of study." It is a computer aided methodology to study and structure complex issues into directed graphs which can be easily understood (Poduval and Pramod, 2015). Basically, it is a qualitative analysis that used to identify the interrelationship or precedence relationship among all variables in qualitative data.

ISM is an interactive learning process (Luthra et al., 2011) which is used to transform a set of directly or indirectly related variables into a comprehensive systematic model. ISM is also a well-established technique that developed insights into collective understandings of the relationships between the variables (Attri et al., 2013). Generally, it can be used in identifying precedence relationships among specific items which deal with a complex problem or issues as a complex problem may consist of a number of factors. As described in paper from Luthra et al. (2011), the directly or indirectly related variables describe the situation much more accurate than the individual variables. Thus, ISM is an appropriate technique to help researcher to simplify the process of project.

However, the fundamental objective of ISM is organizational of data without information added. The information added is zero while the value added is structural (Luthra et al., 2011). Since ISM method where the elements within and how the elements are related is decided based on a group discussion, it also been known as interpretive (Pfohl et al., 2011). In order to achieve higher credibility and accuracy of the result, a group of trustworthy experts who are knowledgeable of the problem's context is necessary.

ISM has been used in analyzing the factors that impeding TPM implementation (Poduval and Pramod, 2015). Poduval and Pramod (2015) applied ISM analysis as a precursor to deal with the barriers in TPM implementation and ISM basics. Poduval and Pramod (2015) concluded that ISM is the appropriate method in order to study the interrelationship among factors listed. Besides, ISM has been applied to supply chain management background for modeling supply chain list (Pfohl et al., 2011). Pfohl et al. (2011) claimed that ISM is described as interpretive which showing whether and how the elements are related. Thus, ISM is structuring as it produces a comprehensive structure of all the complex elements by considering all possible interactions between elements. In addition, ISM was applied by Dev et al. (2014) in order to perform the reconfiguration of supply chain network in identifying the mutual relationship of the enablers among various enablers by conducting experiments through simulation of a hypothetical supply chain network.

Through the reviews, ISM is an appropriate tool not only for investigating the interrelationships of certain system such as TPM and SCM, but also can be used in determining the precedence relationship of the lean key determinants in this research. Hence, ISM was applied in this research as it can provide a clearer diagram that shows the interrelationships among each variable. Moreover, the driving power and dependence level of variables can be known as well through ISM diagram.

\section{Problem description}

Holweg (2007) mentioned that LM is a huge management topic that consists of collective of lean tools to solve different problem encounter in different industry. However, with the lack of information regarding the lean key determinants in the overall manufacturing sectors in Malaysia (Wong and Wong, 2011; Nordin et al., 2010), there is an urgent need to examine the lean key determinants and determine the precedence relationship among key determinants.

Despite of few researches done on determinants of LM implementation, the background of research are mainly focused on manufacturers in developed countries, and each of them have introduced a group 
of determinants particular to their study. Hence, the research results cannot be freely generalized to Malaysian manufacturers. Although various factors were highlighted as potential determinants, it cannot be expected from Malaysian manufacturers to ensure the existence of all potential facilitator of LM implementation as this will incurred significant cost. Thus, a blind effort to facilitate all determinants of LM, regardless of their potential effect within Malaysian manufacturing industry, is ill-advised. Therefore, there is a significant need for research on key determinants of LM implementation among Malaysian manufactures.

Additionally, there is an inexistence of knowledge on interaction among key determinants with regard to their impact on LM effectiveness. This particular gap is not merely limited to Malaysia, and to the best of the researcher's knowledge, no study by far on investigating the precedence relationships among determinants of LM implementation. Even though the potential determinants of LM implementation might be known, the precedence relationships of determinants should be facilitated (Womack et al., 1990). For instance, the organizations have to understand the precedence relationships of key determinants in order to have better strategy on LM implementation. With the lack of informative knowledge and experience on organizing these key determinants, issues such as wrong financial strategies, miscommunication among different departments, and wrong HR management strategies will barricade the LM implementation, reduce its effectiveness, and decrease the competitiveness of the business (Al-Aomar, 2011). Furthermore, there is no research on lean key determinants in Malaysia with its precedence relationship being defined.

With the brief discussions mentioned above, existing problems in the research context can be summarized as follow:

i. Lack of knowledge on the key determinants of LM implementation among Malaysia manufacturing sector;

ii. Lack of knowledge on how the interaction among key determinates of LM can result in LM implementation effectiveness.

Lack of understanding on the precedence relationships among different determinates of LM.

\section{Solution methodology}

ISM is an important and appropriate analysis tool to explore the basis relationship between attributes and also extracts the overall structure to provide a proper sequence of arrangement for the attributes. However, ISM is only a tool to figure out the direction and order for the complex relationship of variables, it does not provide the significance of variables weightage (Ravi and Shankar, 2005).

According to Govindan et al. (2012), the analyzing elements of ISM are purely based on their interviewed company. In this paper, comprehensive reviews of determinants of LM were done in order to set the key determinants of LM effectiveness. After the key determinants were determined, an interview section with lean experts was carried out to conclude the key determinants of lean implementation. ISM methodology was then applied to determine the precedence relationship of each key determinant. Total 180 reputable journal papers about key determinants of LM were reviewed by the researcher. The ranking of most discussed key determinants in those journals are summarized as Table 1.

Table 1: Ranking for most discussed Key Determinants from 180 journals reviewed

\begin{tabular}{cc}
\hline Key Determinants of Successful LM Implementation & Rank \\
\hline Managerial Support & 1 \\
Investment Cost & 4 \\
Employee empowerment & 3 \\
Effective leadership & 2 \\
Awareness of latest lean information & 5 \\
Information technology & 6 \\
Maintenance of Machine & 13 \\
Relationship with supplier & 11 \\
Employee Involvement & 7 \\
Skill and Expertise & 12 \\
Organization Culture & 8 \\
Human attitude & 14 \\
Lean Implementation Techniques & 10 \\
Strategy & 9 \\
Benchmarking & 15 \\
\hline
\end{tabular}

The most discussed lean key determinants according to descending sequence are Managerial Leadership and Support, Effective Leadership, Employee Empowerment, Investment Cost, Awareness of Latest Lean information, Information Technology, Employee Involvement, Organization Culture, Strategy, and Lean Implementation Technique, Relationship with supplier, Skill and Expertise, Maintenance of Machine, Human attitude, and Benchmarking.

Afterwards, interview sessions were carried out with four LM experts from a lean awarded copper manufacturing company. Based on their professional experience in lean, they concluded that the factors in Table 2 are the key determinants of lean effectiveness.

After the journal reviewed and interview section, researcher is then analyses the data by using ISM. Eventually, a preliminary model with the contextual relationship among the attributes will be able to create by using the ISM tools such as Structural SelfInteraction Matrix (SSIM) for main attributes and Level partition. ISM approach is a modeling technique. Each step is relevant with each other and cannot be bypassed. The summary flowchart of ISM analysis was shown in Fig. 1.

\section{Application of model to the case illustration}

ISM is being applied to address complex problems or issues. Researchers such as Kannan and Choon Tan (2006) and Luthra et al. (2014) have used ISM methodology in order to modeling various variables in their project. 
Table 2: Attributes and definition

\begin{tabular}{|c|c|}
\hline Attributes & Definition \\
\hline Employees & Giving employees certain degree of \\
\hline $\begin{array}{l}\text { Empowerment } \\
\text { (EE) }\end{array}$ & $\begin{array}{l}\text { responsibility and authority in decision } \\
\text { making with respect their specific task. } \\
\text { Participation of employees in different }\end{array}$ \\
\hline $\begin{array}{c}\text { Employees } \\
\text { Involvement (EI) }\end{array}$ & $\begin{array}{l}\text { activities that help organization to meet its } \\
\text { objectives by applying their own ideas, } \\
\text { expertise and efforts. }\end{array}$ \\
\hline $\begin{array}{l}\text { Implementation } \\
\text { Cost (IC) }\end{array}$ & $\begin{array}{l}\text { Investment cost that used to implement LM } \\
\text { including training cost set up costs, } \\
\text { consultation fees. }\end{array}$ \\
\hline Teamwork (TW) & $\begin{array}{l}\text { United actions of one group of people that } \\
\text { always have significant improve in } \\
\text { effectiveness and efficiency. }\end{array}$ \\
\hline Managerial & Support and commitment from top \\
\hline $\begin{array}{l}\text { Leadership and } \\
\text { Support (MLS) }\end{array}$ & $\begin{array}{l}\text { management that giving confidence to } \\
\text { employee in order to stay with organization }\end{array}$ \\
\hline $\begin{array}{l}\text { Awareness of } \\
\text { Latest Lean } \\
\text { Information (ALI) }\end{array}$ & $\begin{array}{l}\text { The raise of consciousness and concern in } \\
\text { the latest lean information }\end{array}$ \\
\hline & $\begin{array}{l}\text { Refers to both human and technological IT } \\
\text { investments. Technological IT investment } \\
\text { refers to the investment in any sort of } \\
\text { tangible and intangible technology and }\end{array}$ \\
\hline $\begin{array}{c}\text { Information } \\
\text { Technology (IT) }\end{array}$ & $\begin{array}{l}\text { infrastructure that collect, store, process or } \\
\text { transfer any sort of data and information. }\end{array}$ \\
\hline & $\begin{array}{l}\text { Human IT investment refers to any financial } \\
\text { investment with the purpose of increasing } \\
\text { any type of IT knowledge and expertise all } \\
\text { throughout the organization. }\end{array}$ \\
\hline
\end{tabular}

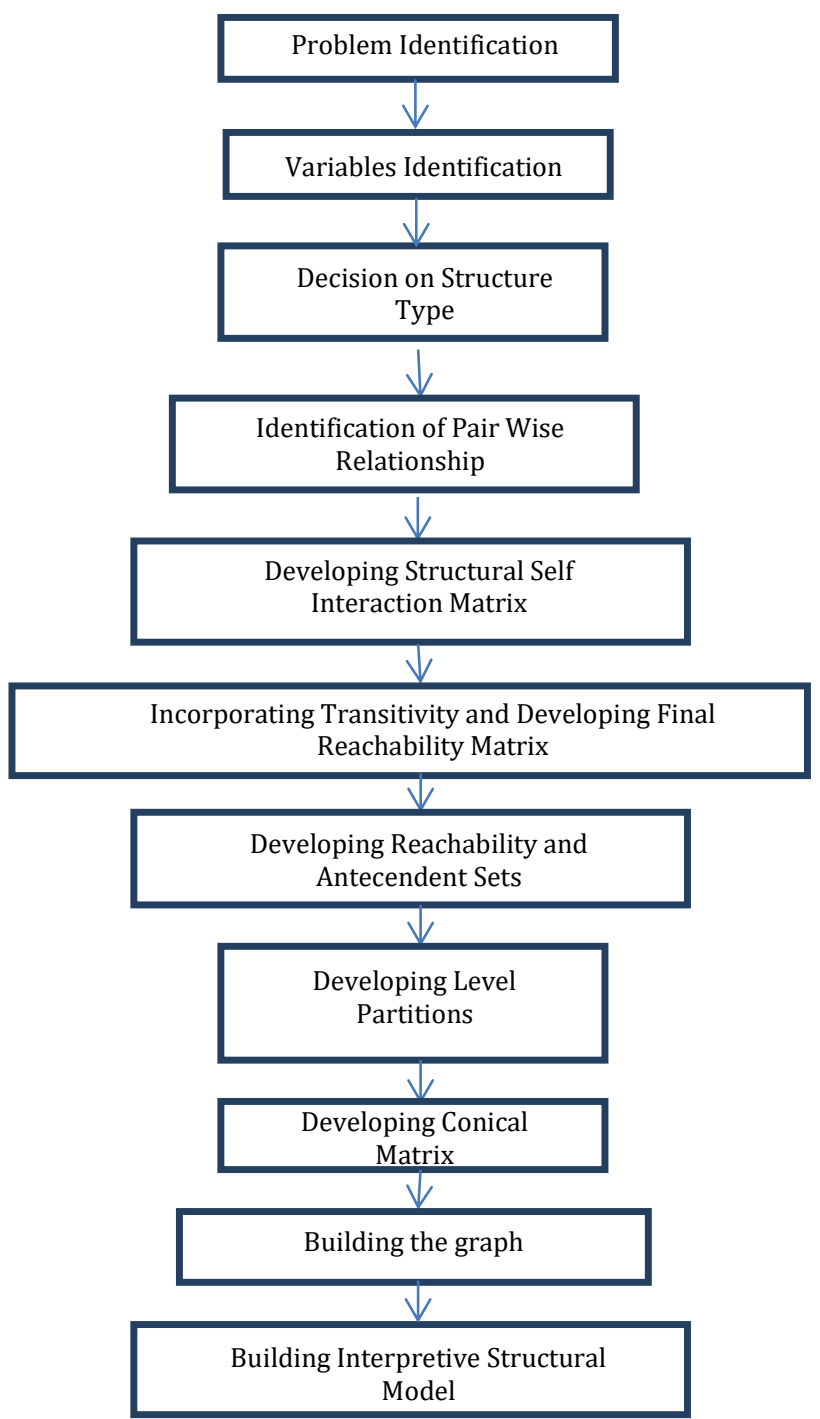

Fig. 1: Block diagram of ISM processes (Poduval and Pramod, 2015)
Thus, ISM was selected in this paper in order to have clearer understanding on the precedence relationships among key determinants. By go through this method, a set of directly or indirectly related variables will be structured in to a comprehensive systematic model. The model is then formed portrays the structure in a designed diagram model (Sage, 1997). Attri et al. (2013) gave a definition towards ISM as a process which will transform unclear, poorly articulated mental models of systems into a well-defined models.

\subsection{Structural self-interaction matrix (SSIM)}

Table 3 shows the SSIM for main attributes, which is the factors affecting LM effectiveness. With the vertical column as attribute $i$, and horizontal row as attribute $j$, the self-interaction of each variables is determined according to the feedback given by lean experts. In SSIM, abbreviation as shown as below:

V: attribute i will help to alleviate attribute j;

A: attribute i will be alleviated by attribute j;

$\mathrm{X}$ : attributes $\mathrm{i}$ and $\mathrm{j}$ will help to achieve each other;

0 : attributes $\mathrm{i}$ and $\mathrm{j}$ are unrelated.

For example:

ALI will help to alleviate IT (V)

TW will be alleviated by IT (A)

IT and EE are not relevant to each other (O)

Table 3: Structural Self-Interaction Matrix (SSIM) for main attributes

\begin{tabular}{cccccccc}
\hline i & IT & ALI & MLS & TW & IC & EI & EE \\
\hline EE & 0 & 0 & A & O & O & O & - \\
EI & O & O & A & V & O & - & \\
IC & 0 & A & O & 0 & - & & \\
TW & A & O & A & - & & & \\
MLS & O & A & - & & & & \\
ALI & V & - & & & & & \\
IT & - & & & & & & \\
\hline
\end{tabular}

\subsection{Initial reachability matrix}

Table 4 shows the initial reachability matrix for the main variables. This step is mainly done to find out if there are any relationship in between two variables, or to the own variable itself. The substitution of 1 and 0 are summarized as below:

- In Table 4, attribute $i$ will help to alleviate attribute $j,(V)$, will be marked with " 1 ".

- In Table 4, attribute $i$ will be alleviated by attribute $j$, (A), will be marked with " 0 ".

- In Table 4, attribute $i$ and attribute $j$ are unrelated, (O), will be marked with " 0 ".

- In Table 4, attribute $i$ and attribute $j$ will help to achieve each other, $(X)$, will be marked with " 1 ".

- All the relationship to its own attributes are marked with "1".

\subsection{Final reachability matrix}

Table 5 shows the final reachability matrix for main attributes of those determinants of LM. 
Transitivity is defined as if A leads to B and B leads to $\mathrm{C}$, then $\mathrm{A}$ is indirectly lead to $\mathrm{C}$. The indirect pathways of alleviations is marked with symbol " 1 *". The indirect relationship meaning there is another variable that plays as mediator before approaching attributes $j$. After that, Table 6 shows the final reachability matrix with driving power and dependence for main attributes. The driving power was calculated by counting the total amount of symbol "1" for horizontal row. The vertical column (j) shows the dependence level for the main attributes. By calculating the number of symbol " 1 " for each vertical column, the dependence level for each attribute can be determined.

\subsection{Level partition-iteration}

Table 7 shows the first iteration for level partition of main attributes from Table 6. At the reachability set column, all the attributes $j$ marked with symbol " 1 " or " $1 *$ " are listed for the attribute $i$. Reachability set consists of the variable itself and other variable which it may help to alleviate.

Table 4: Initial reachability matrix for main attributes

\begin{tabular}{cccccccc}
\hline EE & 1 & 0 & 0 & 0 & 0 & 0 & 0 \\
EI & 0 & 1 & 0 & 1 & 0 & 0 & 0 \\
IC & 0 & 0 & 1 & 0 & 0 & 0 & 0 \\
TW & 0 & 0 & 0 & 1 & 0 & 0 & 0 \\
MLS & 1 & 1 & 0 & 1 & 1 & 0 & 0 \\
ALI & 0 & 0 & 1 & 0 & 1 & 1 & 1 \\
IT & 0 & 0 & 0 & 1 & 0 & 0 & 1 \\
\hline
\end{tabular}

Table 5: Final reachability matrix for main attributes

\begin{tabular}{cccccccc}
\hline$j$ & EE & EI & IC & TW & MLS & ALI & IT \\
\hline EE & 1 & 0 & 0 & 0 & 0 & 0 & 0 \\
EI & 0 & 1 & 0 & 1 & 0 & 0 & 0 \\
IC & 0 & 0 & 1 & 0 & 0 & 0 & 0 \\
TW & 0 & 0 & 0 & 1 & 0 & 0 & 0 \\
MLS & 1 & 1 & 0 & 1 & 1 & 0 & 0 \\
ALI & $1^{*}$ & $1^{*}$ & 1 & $1^{*}$ & 1 & 1 & 1 \\
IT & 0 & 0 & 0 & 1 & 0 & 0 & 1 \\
\hline
\end{tabular}

Table 6: Final reachability matrix with driving power and dependence for main attributes

\begin{tabular}{|c|c|c|c|c|c|c|c|c|c|}
\hline $\mathrm{C}_{i} \mathrm{P}^{\mathrm{j}}$ & $\mathrm{EE}$ & EI & IC & TW & MLS & ALI & IT & Driving power & Rank \\
\hline $\mathrm{EE}$ & 1 & 0 & 0 & 0 & 0 & 0 & 0 & 1 & IV \\
\hline EI & 0 & 1 & 0 & 1 & 0 & 0 & 0 & 2 & III \\
\hline IC & 0 & 0 & 1 & 0 & 0 & 0 & 0 & 1 & IV \\
\hline TW & 0 & 0 & 0 & 1 & 0 & 0 & 0 & 1 & IV \\
\hline MLS & 1 & 1 & 0 & 1 & 1 & 0 & 0 & 4 & II \\
\hline ALI & $1^{*}$ & $1^{*}$ & 1 & $1^{*}$ & 1 & 1 & 1 & 7 & I \\
\hline IT & 0 & 0 & 0 & 1 & 0 & 0 & 1 & 2 & III \\
\hline Dependence & 3 & 3 & 2 & 5 & 2 & 1 & 2 & & \\
\hline Rank & II & II & III & I & III & IV & III & & \\
\hline
\end{tabular}

Antecedent set consists of itself and the other variables that may help in alleviating it. Basically, reachability set depends on the attributes' driving power while the antecedent set depends on its' dependence level. The intersection of variables in reachability set and antecedent set are found and listed in the intersection column. When the intersection set happened to be exactly the same as the factor, then the first iteration is obtained and recorded in the Level column as "I". Same analogy applied to the remaining variables. After the first iteration is completed, level 1 attribute is then discarded. The procedure is repeated on the remaining attribute to determine the next level attribute. These iterations are repeated until the level of each attribute is classified. Iteration 1, iteration 2, iteration 3 and iteration 4 are shown at Table 7, Table 8, Table 9 and Table 10 respectively. The digraph of the precedence relationship among key determinants is shown in Fig. 2.

Table 7: Level partition-iteration 1 (main attributes)

\begin{tabular}{|c|c|c|c|c|}
\hline Factors & Reachability set (predicted by) & Antecedent set (predicted with) & Intersection set & Level \\
\hline \multicolumn{5}{|c|}{ Iteration 1} \\
\hline $\mathrm{EE}$ & $\mathrm{EE}$ & EE, MLS, ALI & $\mathrm{EE}$ & I \\
\hline EI & EI, TW & EI, MLS, ALI & EI & \\
\hline IC & IC & IC, ALI & IC & I \\
\hline TW & TW & EI, TW, MLS, ALI, IT & TW & I \\
\hline MLS & EE, EI, TW, MLS & MLS, ALI & MLS & \\
\hline ALI & EE, EI, IC, TW, MLS, ALI, IT & ALI & ALI & \\
\hline IT & TW, IT & IT, ALI & IT & \\
\hline
\end{tabular}

Table 8: Level partition-iteration 2 (main attributes)

\begin{tabular}{ccccc}
\hline Factors & Reachability set & Antecedent set & Intersection set & Level \\
\hline & & Iteration 2 & & \\
EI & EI & EI, MLS, ALI & EI & II \\
MLS & EI, MLS & MLS, ALI & MLS & \\
ALI & EI, MLS, ALI, IT & ALI & ALI & \\
IT & IT & IT, ALI & IT & II \\
\hline
\end{tabular}

Table 9: Level partition-iteration 3 (main attributes)

\begin{tabular}{ccccc}
\hline Factors & Reachability set & Antecedent set & Intersection set & Level \\
\hline \multicolumn{5}{c}{ Iteration 3} \\
MLS & MLS & MLS, ALI & MLS & III \\
ALI & MLS, ALI & ALI & ALI & \\
\hline \multicolumn{5}{c}{108}
\end{tabular}


Table 10: Level partition-iteration 4 (main attributes) factors

Factors Reachability set Antecedent set Intersection set Level

\begin{tabular}{ccccc}
\multicolumn{5}{c}{ Iteration 4} \\
ALI & ALI & ALI & ALI & IV \\
\hline
\end{tabular}

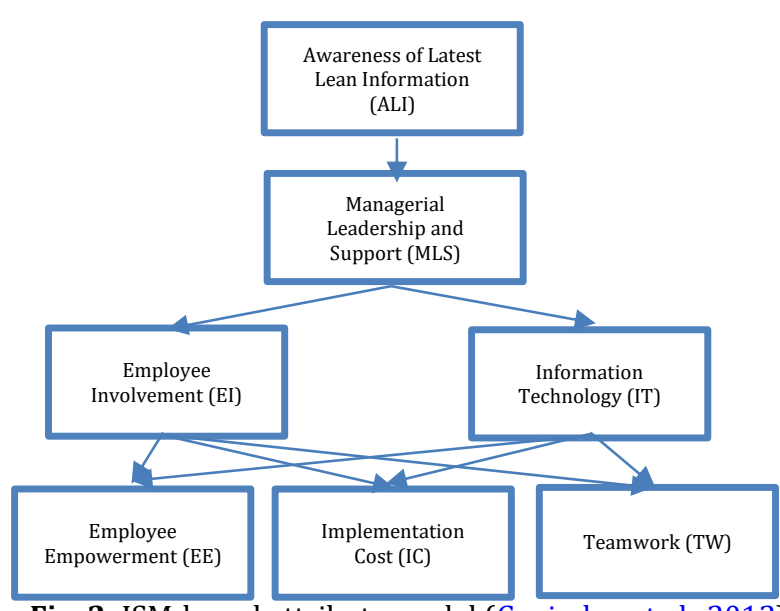

Fig. 2: ISM-based attribute model (Govindan et al., 2012)

\subsection{MICMAC analysis}

MICMAC analysis is used to analyze the driving power and dependence power of each attribute (Kannan et al, 2006). Fig. 3 shows the driving power and dependence diagram for the factors affecting lean main attributes (Kannan and Haq, 2007). An attribute with strong driving power and weak dependence level is identified as the key variable, which is located at the Section IV in Fig. 3. Attribute that having strong driving power but strong dependence is located at Section III in the chart. Attributes that fall into Section II are considered as having weak driving power but strong dependence level. Meanwhile, attributes that fall into the first cluster (Section I) are considered as having low driving power and low dependence level. However, there are no attribute falls in between the third cluster in this research variable. Moreover, the driving power and dependence level of variables can be known as well through ISM diagram (Kannan and Haq, 2007).

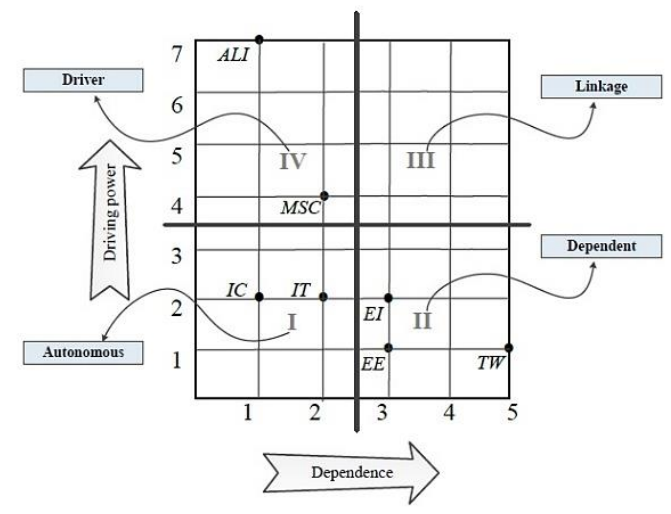

Fig. 3: Driving power and dependence diagram for main attributes

\section{Results and discussion}

ISM not only examined the key determinants of LM implementations as shown in previous section but also showed the precedence relationship of key determinants of lean effectiveness in following sequences: ALI > MLS > EI, IT > EE, IC, TW. The result above concluded that ALI is the most significant attribute that showing the strongest driving power and weakest dependence level among determinants. This means ALI should be first implemented in the organization as lean would not be able to initiate without sufficient lean knowledge adopted by the employees especially the top management. By providing workshop, trainings and seminars, participants can obtain the latest knowledge of lean and have deeper understanding on LM benefits and practice methods. Followed by MLS, the support and encouragement from the management team is important as they are the one to ignite the lean spirit of the other workers in the organization in the entire process of effective lean implementation. After MLS, IT and EI are equivalent and should be implemented simultaneously. The use of IT equipment to keep tracking the daily lean data restored and performing data analysis would be able to enhance the lean effectiveness outcome systematically. Meanwhile, EI is significant in order to ensure every employee is taking part in the lean effectiveness project to produce the best outcome. Lastly, IC, EE and TW showing weakest driving power through ISM analysis. These 3 determinants should be implemented at the same time. IC needs to be funded by the organization in order to improve the lean system by purchasing machines or equipment at the production floor. Besides, EE must be practiced by the top management in order for the lean executer to make decision on certain lean issues instead of restricted their right and will to perform more in the lean activities, however, supervision can be provided upon any decisions made by the employees, therefore TW is crucial when a decision is made. Generally, decision making comes from a group of team member, instead of a single employee to take charge of the entire lean decision as it usually involved entire department or even few departments. In short, the organizations should place high priority on tackling the determinants which have a high driving power and place on the top level of ISM as shown in Fig. 3.

The findings of this study, as guidelines for achievement of LM effectiveness, not only provides necessary steps for successful implementation of lean, but also help lean companies to achieve higher level of lean cost and time savings, while increasing the effectiveness of LM. Furthermore, the finding of precedence relationship between key determinants will be beneficial to Malaysian manufacturers as this finding providing others with good knowledge about pros and cons of LM. In addition, this research can serve as general reference for Malaysia manufacturer before implementing LM by assisting 
them to avoid wrong business strategies and offering the clear consequence of LM implementation. Meanwhile, the developed model in this research can assist the current lean implementer to improve LM effectiveness. However, result of ISM only mapped the precedence relationships between key determinants without the weightage of each determinant.

In addition, the finding of study and related contributions are not only limited to Malaysia, given the study strives to understand the precedence relationships among determinants of LM implementation, and map them for the first time. Keeping in mind the limited generalizability of the findings, the model and guidelines obtained can still be a solid and useful starting point for LM scholars and implementers worldwide, given researchers and practitioners could follow the methodology proposed in this research and further modify and improve it based on the particularities of their study settings.

\section{Conclusion}

In conclusion, this paper examined the key determinants of LM implementation in Malaysia's manufacturing industry and its precedence relationships. In fact, there is no research relating to lean key determinants in Malaysia with its precedence relationship being defined. The findings in this paper would be the first to indicate the importance of precedence relationship among the lean determinants of LM implementation in the aspect of theoretical and practical implication.

In addition, this research shows that the ISM is complementary analytical tools that are essential for initial development of a hypothetical lean model. By using ISM, the data collected throughout this study would be able to go through further empirical testing and strengthen the reliability of the findings.

Despite being limited to Malaysia's manufacturing industry, the ISM model in this paper is representing an important reference to the lean research world. They are the valuable starting point for LM scholars all over the world to better understand the mechanism. This would be a significant theoretical implication that could possibly inspire the LM effectiveness findings in many countries. However, ISM model has not been statistically validated. This approach can be applied in future research in order to test its validity of this model by using quantitative analyse tool such as structural equation modelling (SEM).

Besides, this research clearly mapped the interrelationships among these key determinates and precedence relationship between them. Hence it is easier and simpler to implement LM in Malaysia's manufacturing industry by utilizing the lean key determinants in a proper sequence as suggested in this research. Instead of pursuing all paternal determinants blindly, they can save time and cost to select and implement the right LM tools by focusing on the key determinants findings identified from this research. With the understanding on interrelationship of key determinants, this paper can act as guidelines and serve as general reference for Malaysian manufacturer for successful LM implementation.

\section{Acknowledgement}

We would like to thank Fundamental Research Grant Scheme (with project number FRGS 4450/ N01) for all the financial support in completing the research and paper publication.

\section{References}

Al-Aomar R (2011). Handling multi-lean measures with simulation and simulated annealing. Journal of the Franklin Institute, 348(7): 1506-1522.

Anand G and Kodali R (2009). Simulation model for the design of lean manufacturing systems-a case study. International Journal of Productivity and Quality Management, 4(5-6): 691714

Attri R, Dev N, and Sharma V (2013). Interpretive structural modelling (ISM) approach: An overview. Research Journal of Management Sciences, 2(2): 3-8.

Busch J (2010). Did Toyota's lean supply chain go bad? Available online at: http://spendmatters.com/2010/03/25/didtoyotas-lean-supply-chain-go-bad/

Dev KN, Shankar R, and Kumar Dey P (2014). Reconfiguration of supply chain network: An ISM-based roadmap to performance. Benchmarking: An International Journal, 21(3): 386-411.

Fliedner G and Majeske K (2010). Sustainability: the new lean frontier. Production and Inventory Management Journal, 46(1): 6-13.

Govindan K, Palaniappan M, Zhu Q, and Kannan D (2012). Analysis of third party reverse logistics provider using interpretive structural modeling. International Journal of Production Economics, 140(1): 204-211.

Holweg M (2007). The genealogy of lean production. Journal of Operations Management, 25(2): 420-437.

Kannan G and Haq AN (2007). Analysis of interactions of criteria and sub-criteria for the selection of supplier in the built-inorder supply chain environment. International Journal of Production Research, 45(17): 3831-3852.

Kannan VR and Choon Tan K (2006). Buyer-supplier relationships: The impact of supplier selection and buyersupplier engagement on relationship and firm performance. International Journal of Physical Distribution and Logistics Management, 36(10): 755-775.

Lapinski AR, Horman MJ, and Riley DR (2006). Lean processes for sustainable project delivery. Journal of Construction Engineering and Management, 132(10): 1083-1091.

Luthra S, Garg D, and Haleem A (2014). Green supply chain management: Implementation and performance-a literature review and some issues. Journal of Advances in Management Research, 11(1): 20-46.

Luthra S, Kumar V, Kumar S, and Haleem A (2011). Barriers to implement green supply chain management in automobile industry using interpretive structural modeling technique: An Indian perspective. Journal of Industrial Engineering and Management, 4(2): 231-257.

Moyano-Fuentes J, Sacristán-Díaz M, and José Martínez-Jurado P (2012). Cooperation in the supply chain and lean production adoption: Evidence from the Spanish automotive industry. 
International Journal of Operations and Production Management, 32(9): 1075-1096.

Nordin N, Deros BM, and Wahab DA (2010). A survey on lean manufacturing implementation in Malaysian automotive industry. International Journal of Innovation, Management and Technology, 1(4): 374-380.

Pfohl HC, Gallus P, and Thomas D (2011). Interpretive structural modeling of supply chain risks. International Journal of Physical Distribution and Logistics Management, 41(9): 839859.

Poduval PS and Pramod VR (2015). Interpretive Structural Modeling (ISM) and its application in analyzing factors inhibiting implementation of Total Productive Maintenance (TPM). International Journal of Quality and Reliability Management, 32(3): 308-331.

Ravi V and Shankar R (2005). Analysis of interactions among the barriers of reverse logistics. Technological Forecasting and Social Change, 72(8): 1011-1029.

Sage AP (1997). Interpreting Structural Modeling: Methodology for large scale systems. McGraw-Hill, New York, USA.

Shah R and Ward PT (2003). Lean manufacturing: context, practice bundles, and performance. Journal of Operations Management, 21(2): 129-149.
Shah R and Ward PT (2007). Defining and developing measures of lean production. Journal of Operations Management, 25(4): 785-805.

Warfield JN (1974). Developing subsystem matrices in structural modeling. IEEE Transactions on Systems, Man and Cybernetics, 4(1): 74-80.

Womack JP and Jones DT (2010). Lean thinking: banish waste and create wealth in your corporation. Simon and Schuster, New York, USA.

Womack JP, Jones DT, and Roos D (1990). Machine that changed the world. Simon and Schuster, New York, USA.

Wong YC and Wong KY (2011). Approaches and practices of lean manufacturing: The case of electrical and electronics companies. African Journal of Business Management, 5(6): 2164-2174.

Yang MGM, Hong P, and Modi SB (2011). Impact of lean manufacturing and environmental management on business performance: An empirical study of manufacturing firms. International Journal of Production Economics, 129(2): 251 261. 